\title{
Carbon balance double agents
}

Glob. Change Biol. http://doi.org/c3nt (2019).

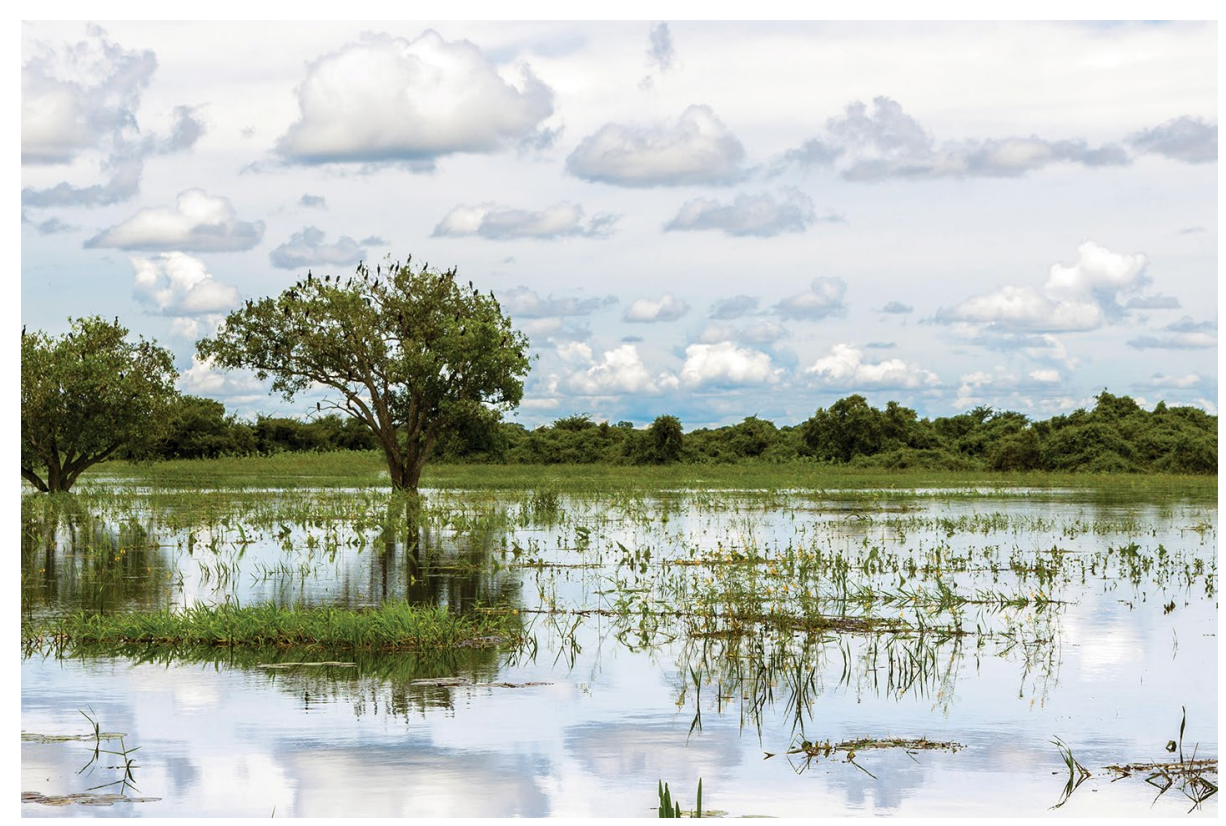

Credit: Filipe Frazao / Alamy Stock Photo

Wetlands are the main natural sources of methane $\left(\mathrm{CH}_{4}\right)$ and account for onethird of total global $\mathrm{CH}_{4}$ emissions. At the same time, they may represent sizeable carbon sinks because of their high primary productivity and the sequestration potential provided by seasonal or permanent anaerobic conditions of their flooded surfaces. To quantify the impact on the global carbon cycle of wetlands, Higo J. Dalmagro from the Universidade de Cuiabá, Brazil, and colleagues have analysed the carbon dioxide $\left(\mathrm{CO}_{2}\right)$ and $\mathrm{CH}_{4}$ net ecosystem fluxes in the extensive, seasonally flooded forests of the largest continuous wetland in the world, the Pantanal of South America.

Thirty percent of the Earth's wetlands are located in the tropics and so understanding how carbon fluxes occur in these ecosystems is critical. The researchers found that seasonally flooded forests were a significant carbon sink during anaerobic conditions between 2014-2017. However, they estimate that combined $\mathrm{CO}_{2}$ and $\mathrm{CH}_{4}$ fluxes potentially represent a source of radiative forcing over 20-year and 100-year time frames, respectively. $\mathrm{CO}_{2}$ uptake increases due to enhanced photosynthetic rates in these communities at the beginning of the wet season, but this declines over time as oxygen levels decrease and other processes such as leaf senescence, litter decomposition and soil $\mathrm{CO}_{2}$ efflux become more prevalent. $\mathrm{CH}_{4}$ release to the atmosphere becomes higher in the anaerobic phase during the wet season.

The carbon balance of these forests depends on precipitation patterns and the spatial and temporal extent of flooding. Whether these ecosystems will be allies or enemies in the face of global warming will depend on the specific effect of climate change on regional hydrological dynamics.

\section{Abel Barral}

Published online: 8 April 2019

https://doi.org/10.1038/s41477-019-0407-y 